\title{
A Review on Multicriteria Decision Support System and Industrial Internet of Things for Source Code Transformation
}

\author{
Qinxia Hao (iD), ${ }^{1,2}$ Shah Nazir $\left(\mathbb{D},{ }^{3}\right.$ Xiaoxu Gao, ${ }^{4}$ Li Ma, ${ }^{1}$ and Muhammad Ilyas ${ }^{5}$ \\ ${ }^{1}$ School of Communication and Information Engineering, Xi'an University of Science and Technology, Xi'an 710054, China \\ ${ }^{2}$ School of Safety Science and Engineering, Xi'an University of Science and Technology, Xi'an 710054, China \\ ${ }^{3}$ Department of Computer Science, University of Swabi, Swabi, Pakistan \\ ${ }^{4}$ School of Energy Engineering, Xi'an University of Science and Technology, Xi'an 710054, China \\ ${ }^{5}$ Department of Computer Science and IT, University of Malakand, Malakand, Pakistan \\ Correspondence should be addressed to Qinxia Hao; hao_qinxia@sina.com and Shah Nazir; snshahnzr@gmail.com
}

Received 19 December 2020; Revised 30 December 2020; Accepted 7 January 2021; Published 13 January 2021

Academic Editor: Sikandar Ali

Copyright (c) 2021 Qinxia Hao et al. This is an open access article distributed under the Creative Commons Attribution License, which permits unrestricted use, distribution, and reproduction in any medium, provided the original work is properly cited.

\begin{abstract}
The large scale increase of communication and number of devices in the Industrial Internet of Things (IIoT) has rapidly enabled practitioners to make decisions based on multicriteria. Multicriteria decision support systems (MCDSSs) play an important role in decision-making for a particular situation based on several criteria. Making of decision based on multicriteria is the main issues for research community and practitioners of the IIoT. Several decision support systems (DSSs) are offered for making decisions which have the potentiality to support the activities of the decision-making process. The suggested study shows a review on the existing decision support systems for the IIoT for source code transformation which will enable research community and practitioners of the industry to use the existing methods, tools, approaches, and techniques and to provide novel solutions for the smooth industry of Internet of Things.
\end{abstract}

\section{Introduction}

The expansion in the communications and increase of smart devices in the Industrial Internet of Things (IoT) has speedily empowered practitioners and researchers for making decisions according to several criteria. With the passage of time advancements in communication of diverse smart devices in network, rise in population Sensors, actuators, IoT, and others, size of data is increasing. Recent methodologies and approaches on the way to solving issues of the increase of data into diverse natures including value, volume, variety, velocity, and veracity, extracting significant information are challenging issues, DSS is furnished with the control of MCDSS for supporting the decisions maker in right decision in complex situations. Based on the success of MCDSS, practitioners and researcher are endeavouring to incorporate the control of intelligent decision-making for the available alternative [1-3].

DSSs are used in diversity of domains and applications for supporting the decision maker in taking right and appropriate decision. The DSS applications are evidenced in different areas of life. Such applications include the DSS in agriculture, business, energy, and so on [4-15]. Numerous domains and applications have explored methods and theories regarding decision-making for alternatives including from simple to advance, intelligent, and smart systems $[16,17]$. DSS is a dynamic field of research where studies find new approaches for evaluating various criteria, proposing frameworks which are intelligent and robust for improving the potentiality of DSS. Owing to the success of DSS in the process of decision-making, researchers are trying to provide more trustworthy, effective, and robust mechanisms for solving the current as well as the upcoming issues. MCDSS plays an important role in the process of decision-making for a particular situation based on diverse criteria. Decision-making based on multicriteria is the main issue for practitioners and researchers in the area of IIoT. Source code transformation is done for various purposes such as to optimize the efficiency of the source code, 
minimize the source code, and mostly to hide the identity of source code. Various preservation techniques are used for changing or modifying the source code [18-22]. Practitioners are mostly embedding the watermark or digital signature for protecting the identity and ownership of the source code. But due to the advancement of information technology, such watermark and digital signature can be removed. Several DSSs are available for making decisions which have the potentiality for supporting the activities of decisions-making and provide solutions for it. A comprehensive review of the existing approaches should be presented for showing the approaches, tools, and techniques practiced.

The proposed study presents an overview on the available decision support systems for IIoT which will enable practitioners and researchers to study the present methods, tools, approaches, and techniques and to provide novel solutions for the smooth industry of IoT. The study provides a comprehensive report of the existing approaches of DSS used for IIoT.

The paper is organised as follows: Section 2 shows the related work of the existing literature to the proposed study and the approaches for Industrial Internet of Things.

\section{Approaches for IIoT}

Diverse solutions of approaches, techniques, methods, and tools of decision support systems are devised by researchers to tackle different situations of IIoT. These solutions consist of dealing the problems from simple to more complex with various criteria of handling. Liu et al. [23] proposed a framework of IIoT cloud-fog hybrid network for data processing of industry. Based on the experimental results, it was revealed that the planned framework can reduce delay processing of industry data effectively. Sahal et al. [24] studied the strong point and flaws of open source technologies for big data and stream processing to setup its applications for use cases of industry 4.0. Khan et al. [25] offered the idea of IIoT in a novel manner for supporting readers to comprehend the IIoT. Studies presented for research in the area of IIoT are reported and shown. The research highly spots the empowering technologies for the IIoT and the issues to the IIoT. Gulati and Kaur [26] analysed the main opportunities assimilated from the idea of IoT into industry with suggesting reference architecture. A model of ontology was planned to propose the model from a semantic perception. For the relationship management, a method among industrial resources was offered.

Aceto et al. [27] elaborated the comprehensive explanation of the main approaches and technologies used in support of Healthcare 4.0, benefits, the key scenario applications, multidisciplinary issues, and the derivations. Rehman et al. [28] examined the existing technologies of big data analytics, algorithms, and strategies that can rapid the progress of perceptive IIoT framework. Important factors from the literature including applications of industrial analytics, types of analytics, analytics techniques, analytics tools, requirements, and sources of data were classified and characterised. The frameworks and case studies of the diverse accomplishments were reported that have turn a profit by BDA. Ordieres-Meré et al. [29] examined the functional properties and structure of cloud manufacturing and planned a business intelligent architecture for empowering dispensing pertinent KPIs recognized with intrigued process data with the support layer of dependability. The authors [30] offered the concept of IoT data management, the literature associated with data IoT management, and the related way-out and identified challenges of open research.

Alexopoulos et al. [31] proposed the architecture of IIoT, and its detail of expansion to help the service of industrial product system life cycle. Mobile phone services are used as mobile computing in the IoT with mobile apps or through M-Health care system [32]. Younan et al. [33] offered a research with a wide-ranging analysis of the current issues in the literature and recommended the use of technologies for allowing the data study and search in upcoming IoT search engines. They offered two case studies for showing encouraging development on intelligence and smartness of IoT presentations based on the incorporation of information and communication technologies. The smart phone applications were presented for the identification of patients' diseases in the fields of gynaecology and paediatrics [34]. Ge et al. [35] showed a report on the big data technologies in diverse IoT domains for enabling and motivating distribution of knowledge through the domains of IoT. The similarity and difference among the big data technology in dissimilar domain with the technology reusability in the IoT domain were presented. Souza et al. [36] proposed digital twin architecture design guidelines through the incorporation of existing technologies and IIoT.

\section{Analysis of the DSS for IIoT Based on Popular Libraries}

DSS plays a significant role in every field of life. With the advancements of technology and information communication, decision-making on right and appropriate time is a challenging issue for the industrial Internet of things. Taking decision on the right and appropriate time can ultimately lead the industry into success. Diverse approaches have been practiced in order to provide solutions for different situations of the IIoT. Jiang [37] offered a method which initially studies the developments of IoT, technologies associated with smart cities and cloud computing and then emphasized on technology of IoT and cloud computing. Urquhart and Mcauley [38] offered a method for risks lying for IIoT drawn both on the perspectives of technical and regulatory. Humayun et al. [39] showed a wide-ranging description of the growth, prevention, and moderation of Ransomware in the background of IoT. Dachyar et al. [40] presented a comprehensive detail of the 26420 articles published in the IoT field. Gierej [41] offered the concept of the business model for corporations applying technologies of the IIoT. The model is established to support traditional companies in 


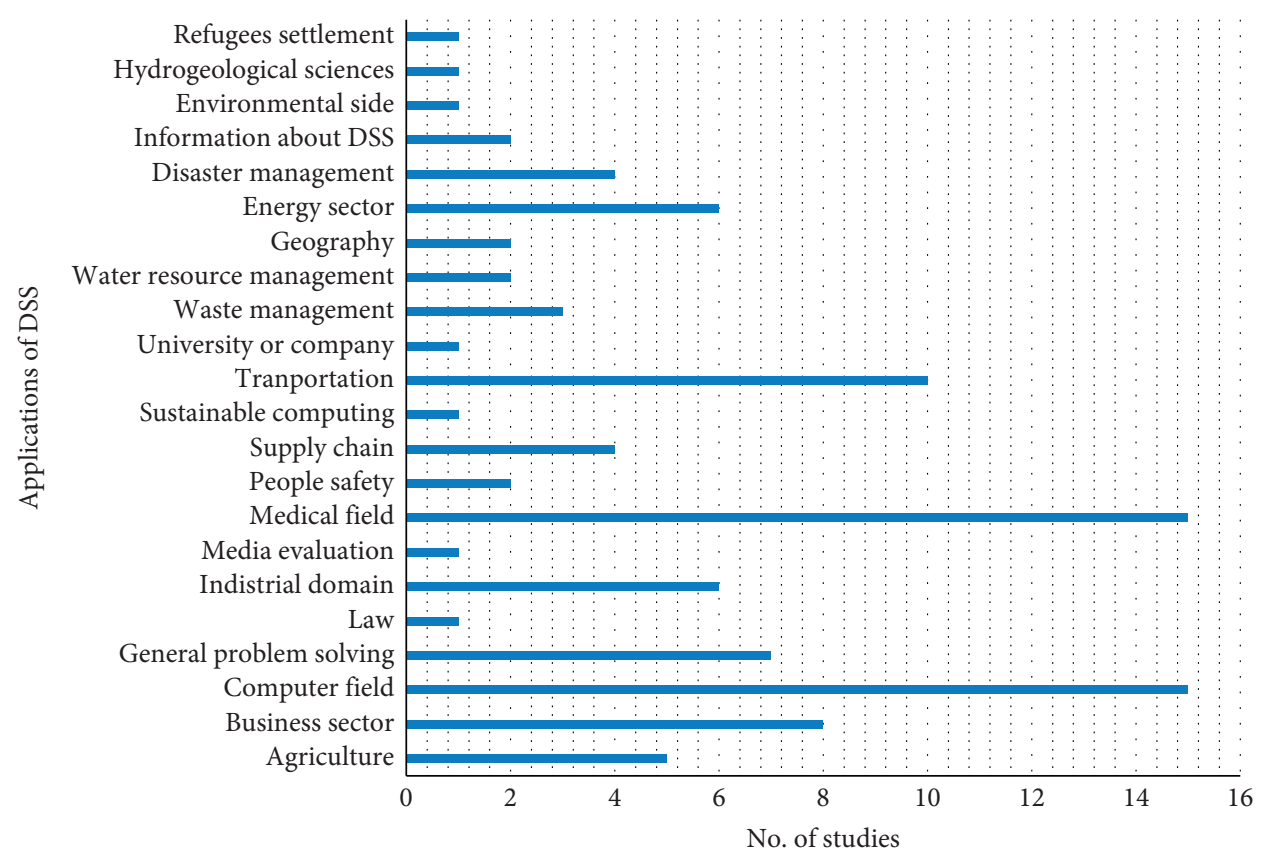

FIgUre 1: Application of the DSS and the studies published.

the evolution of the digital market. Different applications of DSS exist in various areas of research. Figure 1 depicts applications of DSS with studies in different areas.

The proposed study is endeavoured to identify the areas of DSS from diverse perspectives including the type of publications, year of publication, title of publication, and so on. For the initial search process, the query ("multi-criteria") AND ("decision support system" OR “DSS”) AND ("Industrial Internet of Things" OR "IIoT") was searched in the most popular libraries including ScienceDirect, Springer, IEEE, and ACM. Details of each library are given below. For ScienceDirect, the following information was gathered. Figure 2 represents the year-wise paper distributions with the amount of papers published.

Figure 3 depicts publications titles with the total number of publications in the given library. From the figure, it is clear that the higher number of publications were done in the journal of Cleaner Production than in the journal of Future Generation Computer Systems followed by others.

Figure 4 presents the subject areas with the total number of publications in given library.

Figure 5 presents article types with the total number of articles. The figure reveals that the higher number of publications is research articles.

Guo et al. [42] proposed an intelligent DSS on ground of technology of data mining-applied enterprises for establishing of IoT-based smart DSS for the industry of manufacturing. The system supports the decision makers in early decision-making. The experimental results of the study show that the proposed technique of mining technology can analyse the data from various perspective of classifying, clustering, and modelling huge volume of data and identify the correlation between data. Mashal et al. [43] proposed a hybrid approach of multicriteria decision-making which relay on the analytic hierarchy process and simple additive

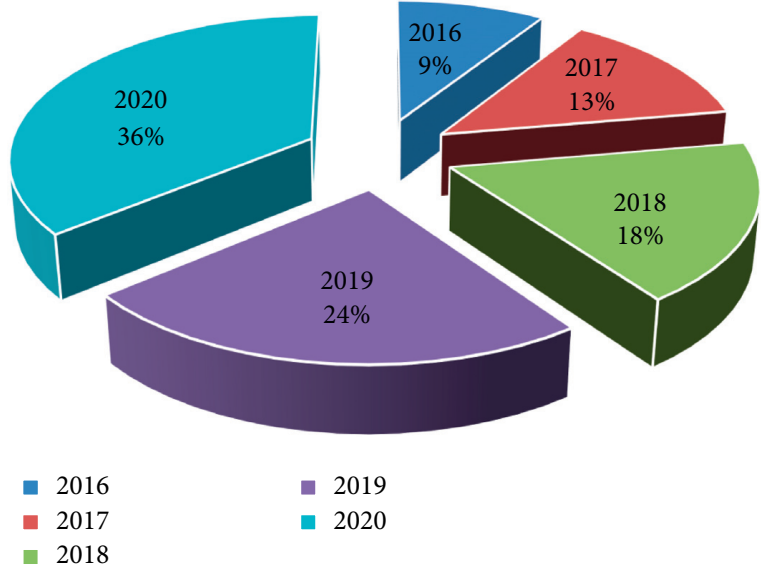

FIgURE 2: Years along with the total number of publications.

weight methods. The results of the study show that the application criterion is significantly important. The reliability, privacy, and availability were considered as the most crucial criteria of the applications of IoT.

After searching the library of ScienceDirect, the library of IEEE was searched in order to get significant information. Kashef et al. [44] proposed a tool of decision support for finding the cost optimum virtual machine settlement on multiclouds. The tool supports the model of cost estimation and optimization algorithm. Various simulations were done for examining the results achieved by the working of tool. Wan and Liao [45] proposed a coupling information system on ground of IoT and DSS exploring the research on the complete framework and design level of integration system. The authors [46] attempted for looking at the requirement of secure IIoT ecosystem in the standard of industry such as OpenFog consortium and industrial Internet consortium. 


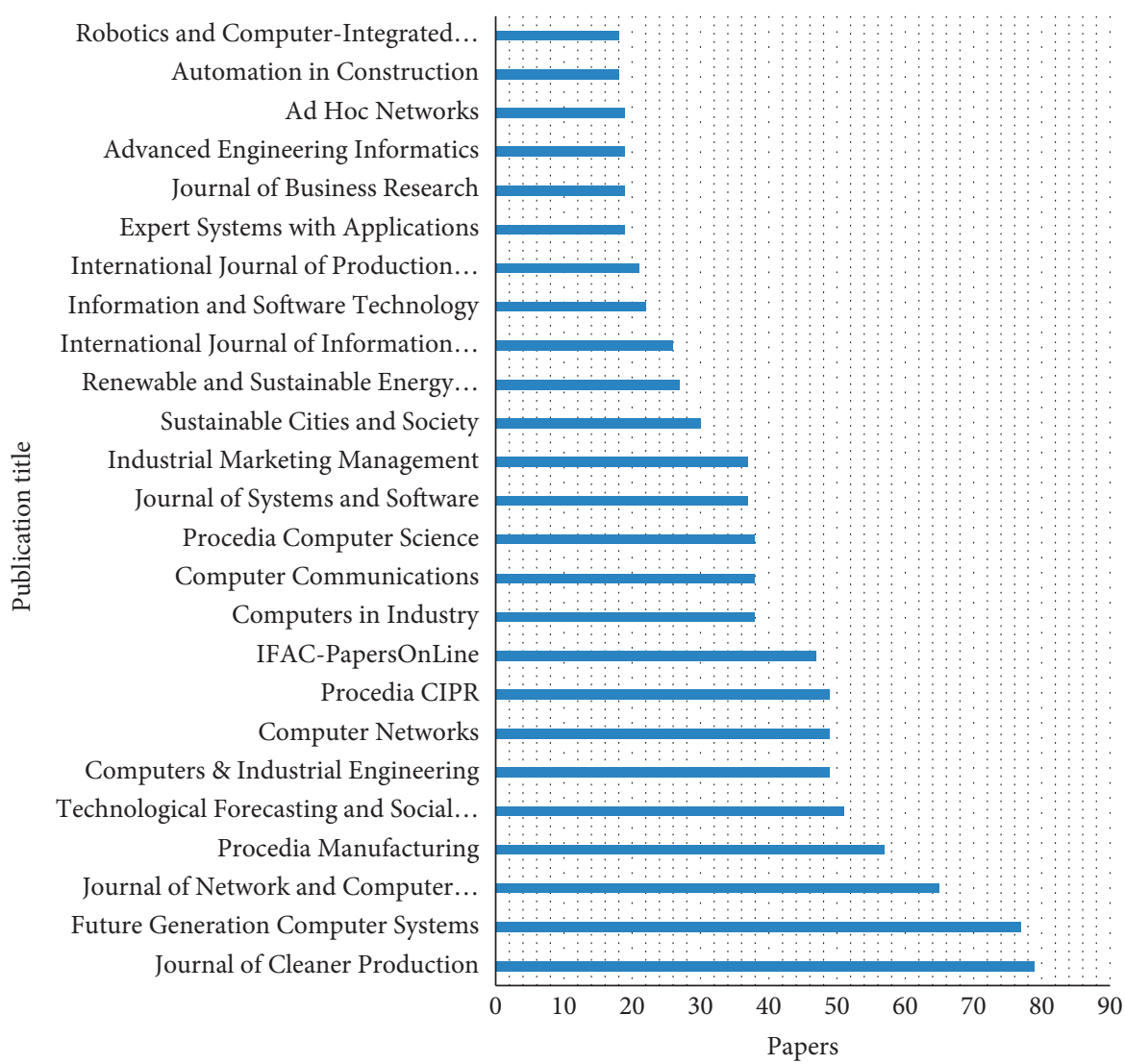

FIgURE 3: Title of publications with total number of publications.

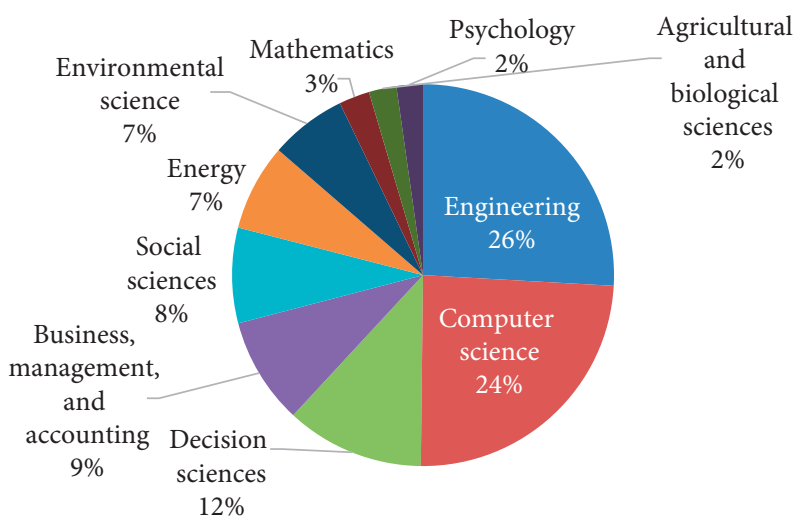

Figure 4: Subject area with articles.

The study discussed the future directions of research for enhancing the privacy, security, and safety of the IIoT. Different types of information were obtained in the library. Figure 6 presents publication topics with the articles published in the IEEE library.

Figure 7 presents publications type with the total number of articles published in the given library. The figure depicts that the most number of paper types were conference followed by journal and then others.

The Springer library was part of the search process for obtaining the associated information. Sha et al. [47] proposed a system called IIoT-SIDefender which measures the

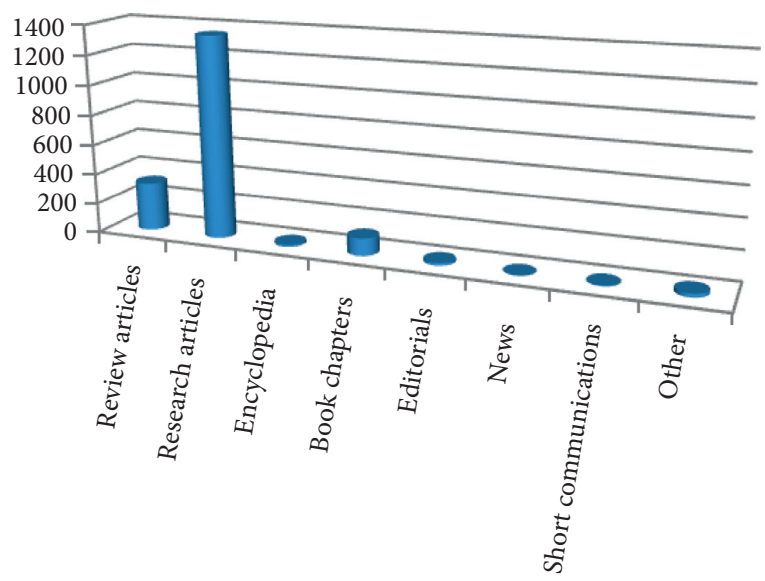

FIgURE 5: Type of articles with the total number of publications.

degree of security of sensitive information with the support of the AHP and TOPSIS. Silva and Jardim-Goncalves [48] proposed an approach for analysing a set of hardware choices according to the user requirements based on multicriteria and advice on appropriate solution of hardware for a particular situation. Figure 8 depicts the types of contents with papers published.

Figure 9 represents the discipline covered by given library with total number of papers.

The ACM library was considered as the relevant library for searching the associated information. Most of the IIoT 


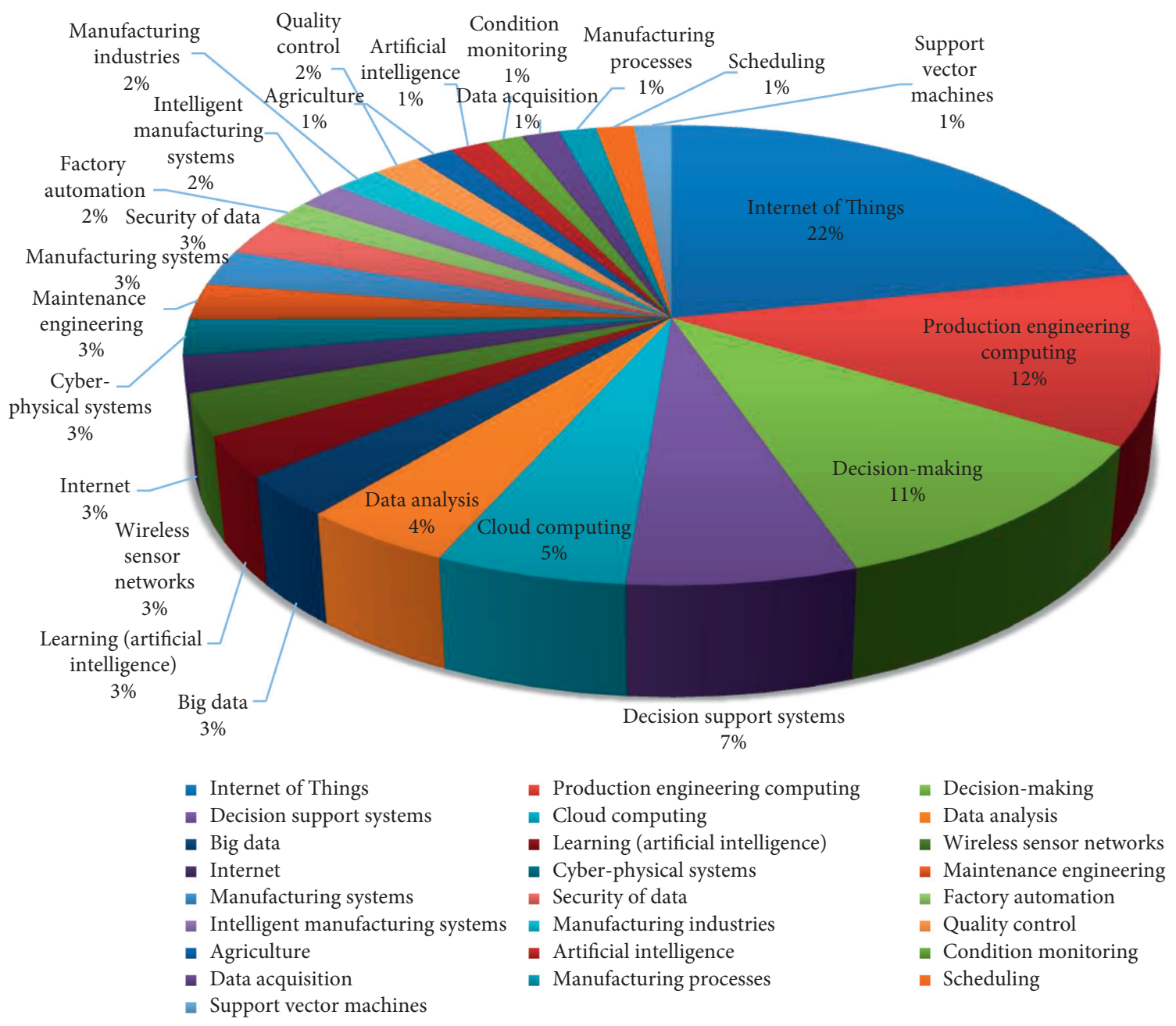

Figure 6: Publication topics along with total number of articles.

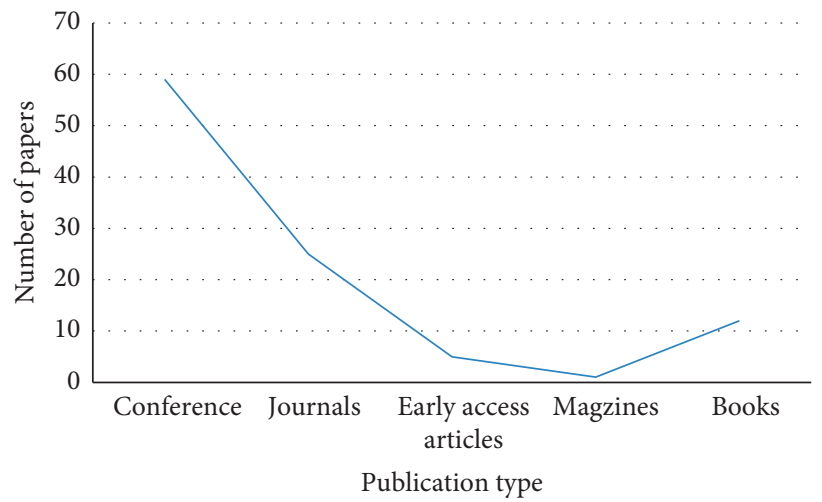

Figure 7: Article type with total number of publications.

based on DSS approaches were considered as part of this library. The study proposed an intelligent approach for facilitating the daily life with the technology of IoT. The ecosystem based on the application of particular network protocol for facilitating the transporting operation [49]. An approach was proposed based on multisensing integrating diagnosis system for real-time and accurate monitoring of large-scale machinery. The approach endeavours capturing and modelling the temporal and spatial structure in sequential data and uses the mode-effective prediction of machinery [50]. Different types of information were gathered from the library of ACM. Figure 10 represents the total number of publications in given years with the total number of papers in the ACM library.

Figure 11 depicts the content types with the papers published. 


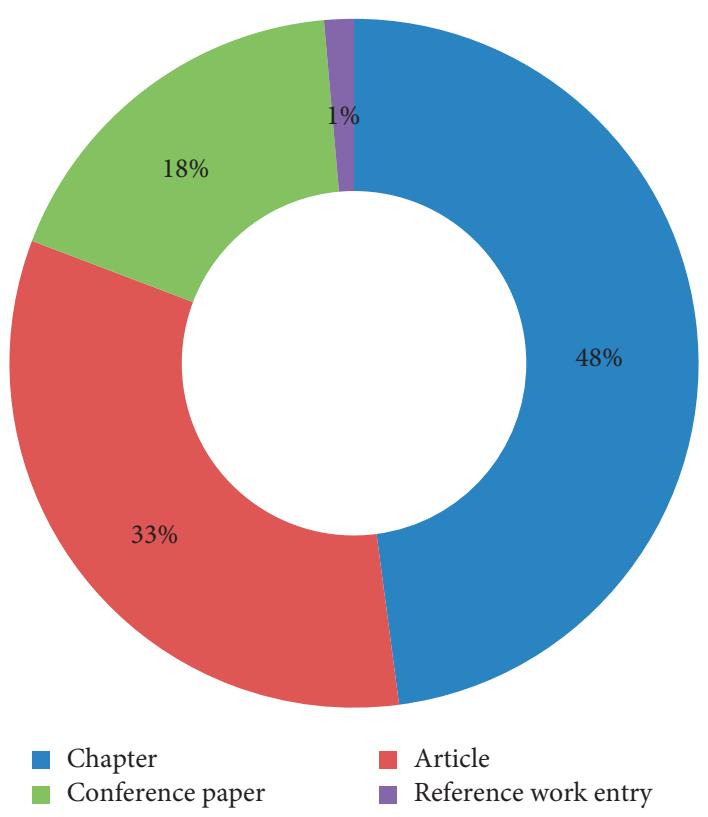

FIgURe 8: Content type with papers.

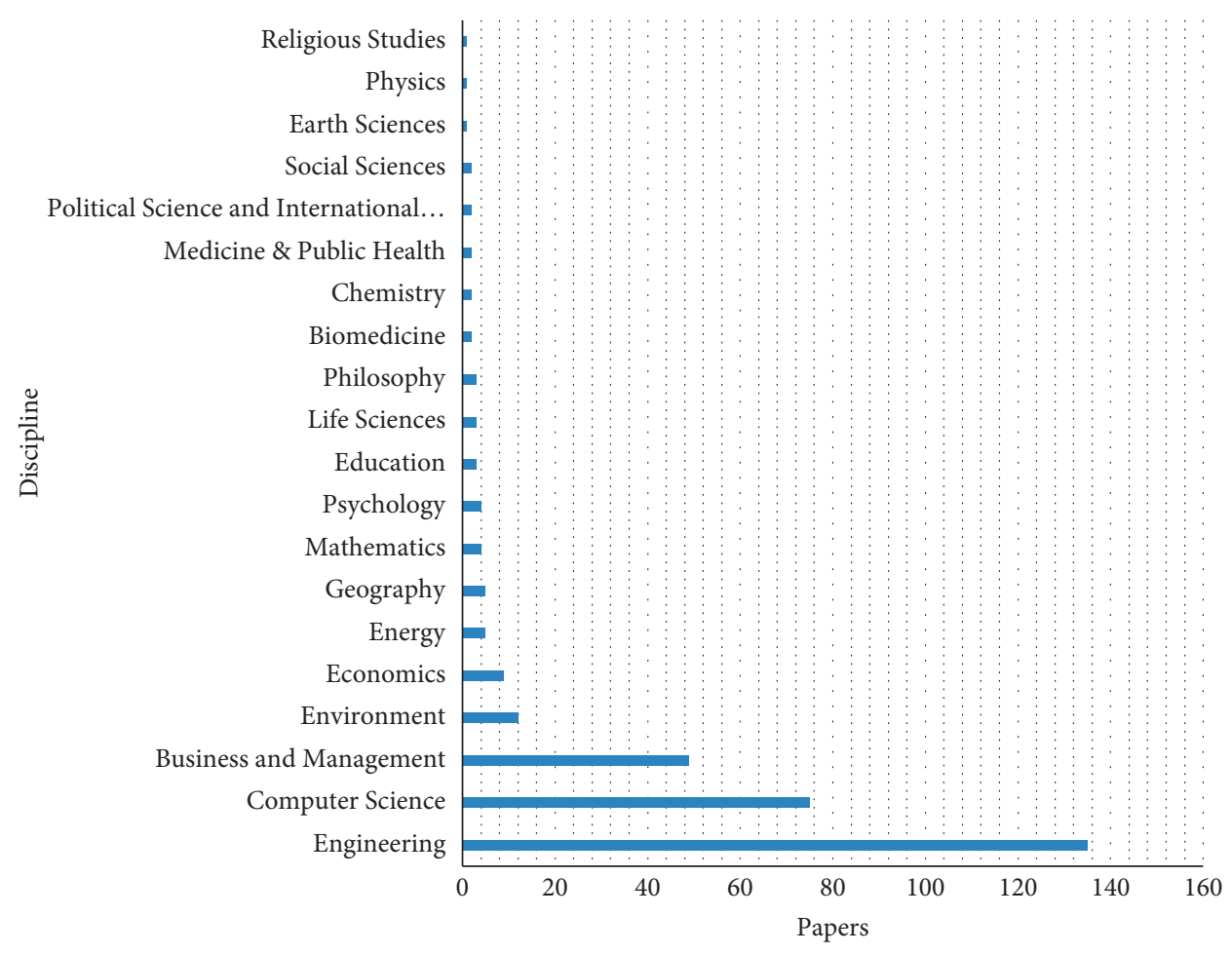

FIgURE 9: Discipline covered with articles. 


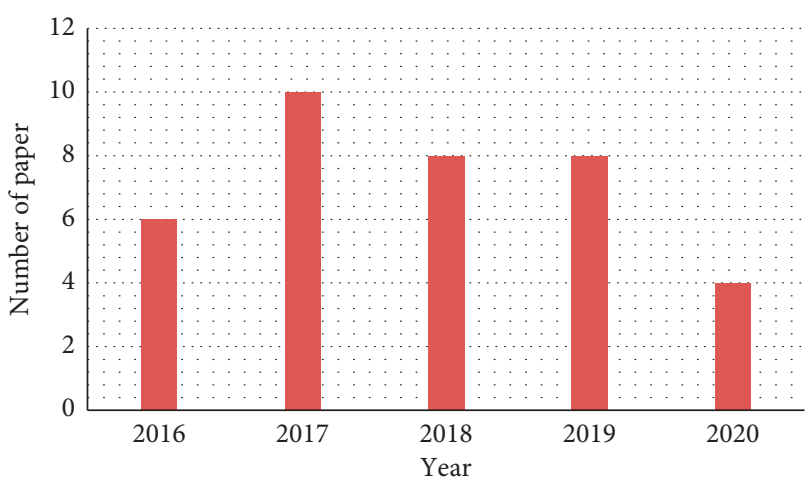

Figure 10: Publications based on the year.

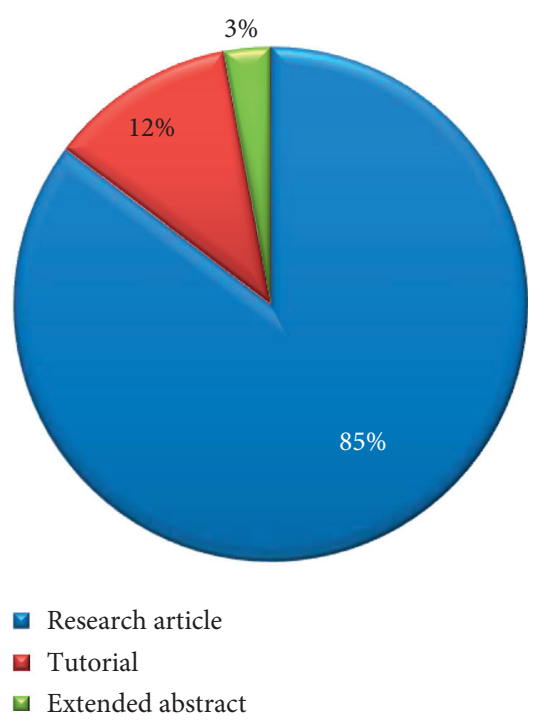

Figure 11: Content types along with the number of papers.

\section{Conclusion}

DSSs are playing a significant role in every field of life. With innovation in technology and information communications, decision-making on right and appropriate time is a challenging issue for the industrial Internet of things. Taking decision on the right and appropriate time can ultimately lead the industry into success. Different libraries were searched in order to identify the applications and domain areas of DSS in various fields of the IIoT. Based on the search process, numerous studies were identified associated with the DSS based on multicriteria in the area of IIoT. The study has exploited the power of DSS as an efficient alternative for solving complex problems of the IIoT based on various criteria for source code transformation. The study has analysed the searched papers from different perspectives of the contributions achieved by researchers in the field. The presented study provides beneficial understanding to the readers and experts of the domain to know the current status of research in order to provide more intelligent and effective solutions to cope with more complex decision-making issues in the field of IIoT.

\section{Data Availability}

No data are available.

\section{Conflicts of Interest}

The authors declare no conflicts of interest.

\section{Acknowledgments}

This work was sponsored in part by Youth Program of National Natural Science Foundation of China (51804248) and Special Project of Education Department of Shaanxi Province, China (14JK1457).

\section{References}

[1] M. Jemmali, M. Alharbi, and L. K. B. Melhim, "Intelligent decision-making algorithm for supplier evaluation based on multi-criteria preferences," in Proceedings of the 2018 1st International Conference on Computer Applications \& Information Security (ICCAIS), pp. 1-5, IEEE, Riyadh, Saudi Arabia, April 2018.

[2] I. Aouadni and A. Rebai, "Decision support system based on genetic algorithm and multi-criteria satisfaction analysis (MUSA) method for measuring job satisfaction," Annals of Operations Research, vol. 256, no. 1, pp. 3-20, 2017.

[3] S. Safdar, S. Zafar, N. Zafar, and N. F. Khan, "Machine learning based decision support systems (DSS) for heart disease diagnosis: a review," Artificial Intelligence Review, vol. 50, no. 4, pp. 597-623, 2018.

[4] I. Petkovics, J. Simon, A. Petkovics, and Z. Covic, "Selection of unmanned aerial vehicle for precision agriculture with multicriteria decision making algorithm," in Proceedings of the 2017 IEEE 15th International Symposium on Intelligent Systems and Informatics (SISY), pp. 000151-000156, IEEE, Subotica, Serbia, September 2017.

[5] C. Fleig, D. Augenstein, and A. Maedche, "Designing a process mining-enabled decision support system for business process standardization in ERP implementation projects," Business Process Management Forum, Springer, Cham, Switzerland, pp. 228-244, 2018.

[6] A. Schwenk-Ferrero and A. Andrianov, "Nuclear waste management decision-making support with MCDA," Science and Technology of Nuclear Installations, vol. 2017, Article ID 9029406, 20 pages, 2017.

[7] T. Ahmad, Y. Ma, M. Yahya, B. Ahmad, and S. Nazir, "Object detection through modified YOLO neural network," Scientific Programming, vol. 2020, Article ID 8403262, 10 pages, 2020.

[8] Hanif-Ur-Rahman, H. K. Bamma, S. Nazir, S. Shahzad, and T. Hodosi, "A sourcing decision model for application maintenance services," in Proceedings of the 3rd International Conference on Science in Information Technology (ICSITech), October 2017.

[9] A. Khan, L. Jian Ping, H. Amin ul et al., "Partial observer decision process model for crane-robot action," Scientific Programming, vol. 2020, Article ID 6349342, 14 pages, 2020.

[10] J. Li, A. Ullah, L. Jun et al., "Attributes based decision making for selection of requirements elicitation techniques using the analytic network process," Mathematical Problems in Engineering, vol. 2020, Article ID 2156023, 13 pages, 2020.

[11] S. Nazir, S. Ali, M. Yang, and Q. Xu, "Deep learning algorithms and multi-criteria decision making used in big data: a 
systematic literature review," Complexity, vol. 2020, Article ID 2836064, 18 pages, 2020.

[12] S. Nazir, S. Shahzad, S. Mahfooz, and M. N. Jan, "Fuzzy logic based decision support system for component security evaluation," International Arab Journal of Information and Technology, vol. 15, no. 2, pp. 1-9, 2015.

[13] S. Nazir, S. Shahzad, A. Ullah, and A. Hussain, "Identification and analysis of project attributes affecting the decision of requirement elicitation technique," in Proceedings of theNational Graduate Conference, Islamabad, Pakistan, March 2017.

[14] H. U. Rehman, M. Khan, Palwasha, H. U. Khan, and S. Nazir, "Analyzing factors that influence offshore outsourcing decision of application maintenance," IEEE Access, vol. 8, 2020.

[15] J. Zhang, S. Nazir, A. Huang, and A. Alharbi, "Multicriteria decision and machine learning algorithms for component security evaluation: library-based overview," Security and Communication Networks, vol. 2020, Article ID 8886877, 14 pages, 2020.

[16] L. S. R. Supriadi and L. Sui Pheng, "Knowledge based decision support system (KBDSS)," in Business Continuity Management in Construction, pp. 155-174, Springer, Singapore, 2018.

[17] A. Alaeddini and K. G. Murty, "DSS (decision support system) for allocating appointment times to calling patients at a medical facility," in Case Studies in Operations Research: Applications of Optimal Decision Making, K. G. Murty, Ed., Springer, New York, NY, USA, pp. 83-109, 2015.

[18] M. Li, S. Nazir, H. U. Khan, S. Shahzad, and R. Amin, "Modelling features-based birthmarks for security of end-toend communication system," Security and Communication Networks, vol. 2020, Article ID 8852124, 9 pages, 2020.

[19] S. Nazir, S. Shahzad, R. B. Atan, and H. Farman, "Estimation of software features based birthmark," Cluster Computing-The Journal of Networks Software Tools and Applications, vol. 21, no. 1, pp. 1-14, 2017.

[20] S. Nazir, S. Shahzad, S. A. Khan, N. Binti Alias, and S. Anwar, "A novel rules based approach for estimating software birthmark," The Scientific World Journal, vol. 2015, Article ID 1579390, 8 pages, 2015.

[21] S. Nazir, S. Shahzad, and N. Mukhtar, "Software birthmark design and estimation: a systematic literature review," Arabian Journal for Science and Engineering, vol. 44, no. 4, p. 3905, 2019.

[22] S. Nazir, S. Shahzad, R. Wirza et al., "Birthmark based identification of software piracy using Haar wavelet," Mathematics and Computers in Simulation, vol. 166, pp. 144-154, 2019.

[23] W. Liu, G. Huang, A. Zheng, and J. Liu, "Research on the optimization of IIoT data processing latency," Computer Communications, vol. 151, pp. 290-298, 2020.

[24] R. Sahal, J. G. Breslin, and M. I. Ali, "Big data and stream processing platforms for Industry 4.0 requirements mapping for a predictive maintenance use case," Journal of Manufacturing Systems, vol. 54, pp. 138-151, 2020.

[25] W. Z. Khan, M. H. Rehman, H. M. Zangoti, M. K. Afzal, N. Armi, and K. Salah, "Industrial internet of things: recent advances, enabling technologies and open challenges," Computers \& Electrical Engineering, vol. 81, p. 106522, 2020.

[26] N. Gulati and P. D. Kaur, "Towards socially enabled internet of industrial things: architecture, semantic model and relationship management," Ad Hoc Networks, vol. 91, p. 101869, 2019.

[27] G. Aceto, V. Persico, and A. Pescapé, "Industry 4.0 and health: internet of things, big data, and cloud computing for healthcare 4.0," Journal of Industrial Information Integration, vol. 18, p. 100129, 2020.

[28] M. H. Rehman, I. Yaqoob, K. Salah, M. Imran, P. P. Jayaraman, and C. Perera, "The role of big data analytics in industrial internet of things," Future Generation Computer Systems, vol. 99, pp. 247-259, 2019.

[29] J. Ordieres-Meré, J. Villalba-Díez, and X. Zheng, "Challenges and opportunities for publishing IIoT data in manufacturing as a service business," Procedia Manufacturing, vol. 39, pp. 185-193, 2019.

[30] B. Diene, J. J. P. C. Rodrigues, O. Diallo, E. L. H. M. Ndoye, and V. V. Korotaev, "Data management techniques for internet of things," Mechanical Systems and Signal Processing, vol. 138, p. 106564, 2020.

[31] K. Alexopoulos, S. Koukas, N. Boli, and D. Mourtzis, "Architecture and development of an industrial internet of things framework for realizing services in industrial product service systems," Procedia CIRP, vol. 72, pp. 880-885, 2018.

[32] S. H. Almotiri, M. A. Khan, and M. A. Alghamdi, "Mobile health (m-health) system in the context of IoT," in Proceeding of the 2016 IEEE 4th International Conference on Future Internet of Things and Cloud Workshops (FiCloudW), pp. 39-42, IEEE, Vienna, Austria, August 2016.

[33] M. Younan, E. H. Houssein, M. Elhoseny, and A. A. Ali, "Challenges and recommended technologies for the industrial internet of things: a comprehensive review," Measurement, vol. 151, p. 107198, 2020.

[34] Y. Karaca, M. Moonis, Y.-D. Zhang, and C. Gezgez, "Mobile cloud computing based stroke healthcare system," International Journal of Information Management, vol. 45, pp. 250261, 2019.

[35] M. Ge, H. Bangui, and B. Buhnova, "Big data for internet of things: a survey," Future Generation Computer Systems, vol. 87, pp. 601-614, 2018.

[36] V. Souza, R. Cruz, W. Silva, S. Lins, and V. Lucena, "A digital twin architecture based on the industrial internet of things technologies," in Proceedings of the 2019 IEEE International Conference on Consumer Electronics (ICCE), pp. 1-2, Las Vegas, NV, USA, Janaury 2019.

[37] D. Jiang, "The construction of smart city information system based on the Internet of Things and cloud computing," Computer Communications, vol. 150, pp. 158-166, 2020.

[38] L. Urquhart and D. McAuley, "Avoiding the internet of insecure industrial things," Computer Law \& Security Review, vol. 34, no. 3, pp. 450-466, 2018.

[39] M. Humayun, N. Z. Jhanjhi, A. Alsayat, and V. Ponnusamy, "Internet of things and ransomware: evolution, mitigation and prevention," Egyptian Informatics Journal, In press.

[40] M. Dachyar, T. Y. M. Zagloel, and L. R. Saragih, "Knowledge growth and development: internet of things (IoT) research, 2006-2018," Heliyon, vol. 5, no. 8, p. e02264, 2019.

[41] S. Gierej, "The framework of business model in the context of industrial internet of things," Procedia Engineering, vol. 182, pp. 206-212, 2017.

[42] Y. Guo, N. Wang, Z.-Y. Xu, and K. Wu, "The internet of things-based decision support system for information processing in intelligent manufacturing using data mining technology," Mechanical Systems and Signal Processing, vol. 142, p. 106630, 2020.

[43] I. Mashal, O. Alsaryrah, T.-Y. Chung, and F.-C. Yuan, “A multi-criteria analysis for an internet of things application recommendation system," Technology in Society, vol. 60, p. 101216, 2020. 
[44] M. M. Kashef, H. Yoon, M. Keshavarz, and J. Hwang, "Decision support tool for IoT service providers for utilization of multi clouds," in Proceedings of the 2016 18th International Conference on Advanced Communication Technology (ICACT), pp. 91-96, Pyeongchang, South Korea, February 2016.

[45] H. Wan and L. Liao, "A coupling system design based on the internet of things and intelligent decision support system in industrial enterprises," in Proceedings of the 2016 3rd International Conference on Information Science and Control Engineering (ICISCE), pp. 753-757, Beijing, China, July 2016.

[46] T. Gebremichael, L. P. I. Ledwaba, M. H. Eldefrawy et al., "Security and privacy in the industrial internet of things: current standards and future challenges," IEEE Access, vol. 8, pp. 152351-152366, 2020.

[47] L. Sha, F. Xiao, W. Chen, and J. Sun, "IIoT-SIDefender: detecting and defense against the sensitive information leakage in industry IoT," World Wide Web, vol. 21, no. 1, pp. 59-88, 2018.

[48] E. M. Silva and R. Jardim-Goncalves, "Multi-criteria analysis and decision methodology for the selection of internet-ofthings hardware platforms," in Proceedings of the Doctoral Conference on Computing, Electrical and Industrial Systems, pp. 111-121, Springer, Costa de Caparica, Portugal, May 2017.

[49] F. Z. Chafi and Y. Fakhri, "The integration of multi agent system within the internet of things: the use of SigFox shield as a network," in Proceedings of the 3rd International Conference on Smart City Applications, pp. 1-8, Tetouan, Morocco, October 2018.

[50] H. Liu, "A multi-sensing collaborative diagnosis system for the reliability of industrial IoT," in Proceedings of the 2019 International Conference on Embedded Wireless Systems and Networks, pp. 391-400, Beijing, China, 2019. 